\title{
Sacral anterior root stimulators for bladder control in paraplegia: the first 50 cases
}

\author{
GS BRINDLEY, CE POLKEY, DN RUSHTON, L CARDOZO \\ From the MRC Neurological Prostheses Unit, Institute of Psychiatry, the Neurosurgical Unit, The Maudsley \\ Hospital, and the Department of Gynaecology, King's College Hospital, London, UK
}

SUMMARY The first 50 patients who have received sacral anterior root stimulator implants are presented, with follow-up of from 1 to 9 years. Forty-nine are alive and 43 are regularly using their implants for micturition. Of the 49 living, 39 are "very pleased, without significant reservations", six are pleased on balance but have reservations, and four are dissatisfied. Residual urine volumes are substantially reduced in all patients who are using their implants. Ten of the 12 female patients and the majority of male patients have become continent. The voiding pressure in implant-driven micturition can be regulated by adjusting the stimulus parameters, and is always kept below $90 \mathrm{~cm}$ $\mathrm{H}_{2} \mathrm{O}$. Of seven patients with ureteric reflux before, operation, four have ceased to reflux and the other three are unchanged. Changes in the radiographic appearances of the bladder have been favourable or zero, but there have been two cases of deterioration in the upper urinary tracts. Significant harmful effects have been CSF leaks, urinary infections following post-operative urodynamic study, and accidental damage to roots. Anterior roots nearly always recover from accidental damage, and posterior roots do not.

Sacral anterior root stimulator implants, intended to improve micturition and achieve continence in patients with disorders of the central nervous pathways of micturition, were developed by the authors, first in baboons ${ }^{1-4}$ and then in patients with spinal injuries. ${ }^{56}$ The present paper describes the first 50 patients to have such implants. Twenty-six of the operations were done at the Maudsley Hospital, London ( 25 of them by one of the authors). Five each were done at the Radcliffe Infirmary, Oxford $(29,30$, 33, 39, 46 of table 1) and Burwood Hospital, Christchurch, New Zealand $(16,17,23,34,45)$, four at the Hallamshire Hospital, Sheffield $(10,21,24,44)$, three at the Centre de l'Arche, Le Mans, France (38, $43,48)$, two each at the Western General Infirmary, Edinburgh $(19,20)$ and the University Hospital, Cardiff $(32,41)$, and one each at Maida Vale Hospital, London (42) and The London Hospital, London (50). All 50 patients except three New Zealanders (23, 34,45 ) have been examined by one or more of the authors after their operations. With the same three

Address for reprint requests: Dr GS Brindley, MRC Neurological Prostheses Unit, Institute of Psychiatry, De Crespigny Park, London SE5 8AF, UK

Received 5 November 1985.

Accepted 13 January 1986 exceptions and two others $(44,46)$, one of us assisted at the operation. The shortest follow-up is 15 months. The longest is seven years for a successful implant and nine years for an unsuccessful one. In the 15 months since completion of the first 50,36 more sacral anterior root stimulators have been implanted. These are not reported here, except for brief mention of one of them.

\section{Patients}

Table 1 shows the most important features of the 50 patients and their operations. Of the 38 men and 12 women, of age ranging from 19 to 57 , two (nos. 1 and 26) had multiple sclerosis, one (no. 35) had a post-traumatic lesion that was presumably a fat embolism of the lumbar cord, and one (no. 22) had a spinal cord compression due to kyphosis, her neurological state altering from little disability to complete paraplegia within a few weeks at the age of 14 years. The remaining 46 had spinal cord injuries, of which 36 were complete and 10 incomplete. Of the ten with incomplete cord injuries, four (nos. 11, 21, 31 and 42) had only posterior column sparing, and six had some sparing of voluntary movement. Four of the six spinal injury patients with some voluntary movement (nos 7, 20, 40 and 49) and both the patients with multiple sclerosis had pain sensitivity in the $\mathbf{S} 2$ to S4 dermatomes. Patients 2-9 of table 1 are patients $1-8$ respectively of references 5 and 6, and 11-15 of table 1 are patients 9-13 respectively of references 5 and 6 .

Criteria for selection In all patients it was proved before 
Table 1 Details of the 50 cases

\begin{tabular}{|c|c|c|c|c|c|c|c|}
\hline \multirow[t]{2}{*}{ Patient No } & \multirow[t]{2}{*}{ Sex } & \multirow{2}{*}{$\begin{array}{l}\text { Age at } \\
\text { operation (yr) }\end{array}$} & \multirow{2}{*}{$\begin{array}{l}\text { Years from injury to } \\
\text { operation }\end{array}$} & \multirow[t]{2}{*}{ Level of lesion } & \multicolumn{3}{|l|}{ Operation } \\
\hline & & & & & $\begin{array}{l}\text { Sacral roots } \\
\text { trapped }\end{array}$ & $\begin{array}{l}\text { Sacral roots } \\
\text { split }\end{array}$ & $\begin{array}{l}\text { Sacral posterior } \\
\text { roots cut }\end{array}$ \\
\hline $\begin{array}{r}1 \\
2 \\
3 \\
4 \\
5 \\
6 \\
7 \\
8 \\
9 \\
10 \\
11 \\
12 \\
13 \\
14 \\
15 \\
16 \\
17 \\
18 \\
19 \\
20 \\
21 \\
22 \\
23 \\
24 \\
25 \\
26 \\
27 \\
28 \\
29 \\
30 \\
31 \\
32 \\
33 \\
34 \\
35 \\
36 \\
37 \\
38 \\
39 \\
40 \\
41 \\
42 \\
43 \\
44 \\
45 \\
46 \\
47 \\
48 \\
49 \\
50\end{array}$ & $\begin{array}{l}\mathbf{F} \\
\mathbf{M} \\
\mathbf{M} \\
\mathbf{M} \\
\mathbf{M} \\
\mathbf{M} \\
\mathbf{F} \\
\mathbf{M} \\
\mathbf{M} \\
\mathbf{M} \\
\mathbf{M} \\
\mathbf{F} \\
\mathbf{M} \\
\mathbf{M} \\
\mathbf{M} \\
\mathbf{F} \\
\mathbf{M} \\
\mathbf{M} \\
\mathbf{M} \\
\mathbf{M} \\
\mathbf{M} \\
\mathbf{F} \\
\mathbf{M} \\
\mathbf{M} \\
\mathbf{M} \\
\mathbf{F} \\
\mathbf{M} \\
\mathbf{M} \\
\mathbf{M} \\
\mathbf{M} \\
\mathbf{M} \\
\mathbf{M} \\
\mathbf{M} \\
\mathbf{M} \\
\mathbf{F} \\
\mathbf{F} \\
\mathbf{M} \\
\mathbf{F} \\
\mathbf{F} \\
\mathbf{M} \\
\mathbf{M} \\
\mathbf{F} \\
\mathbf{M} \\
\mathbf{M} \\
\mathbf{M} \\
\mathbf{M} \\
\mathbf{F} \\
\mathbf{M} \\
\mathbf{M} \\
\mathbf{M}\end{array}$ & $\begin{array}{l}24 \\
38 \\
38 \\
33 \\
43 \\
28 \\
41 \\
32 \\
24 \\
24 \\
27 \\
26 \\
24 \\
41 \\
37 \\
21 \\
28 \\
27 \\
33 \\
36 \\
41 \\
29 \\
22 \\
24 \\
26 \\
57 \\
36 \\
32 \\
32 \\
41 \\
33 \\
19 \\
20 \\
24 \\
24 \\
43 \\
43 \\
31 \\
57 \\
46 \\
25 \\
27 \\
20 \\
43 \\
+ \\
24 \\
56 \\
24 \\
22 \\
25\end{array}$ & 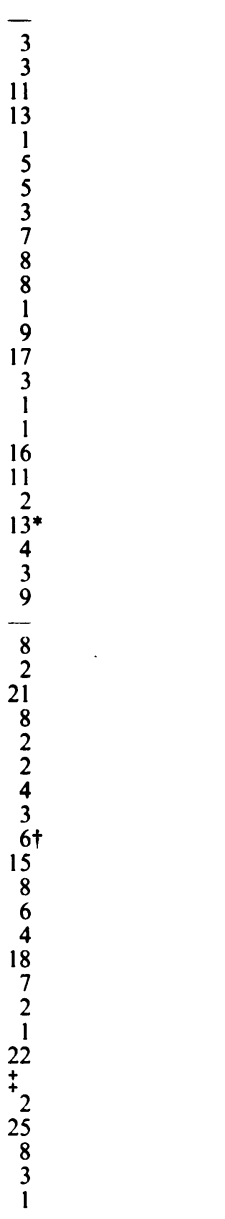 & $\begin{array}{l}\text { MS } \\
\text { T6 } \\
\text { T12 } \\
\text { T9 } \\
\text { C6 } \\
\text { T10 } \\
\text { T8 inc } \\
\text { T5 } \\
\text { T7 } \\
\text { T6 } \\
\text { C6 inc } \\
\text { C6 } \\
\text { C7 } \\
\text { T12 } \\
\text { T6 } \\
\text { T3 } \\
\text { T10 } \\
\text { T6 } \\
\text { T3 } \\
\text { C7 inc } \\
\text { C7 inc } \\
\text { T3 } \\
\text { T7 } \\
\text { T5 } \\
\text { C7 } \\
\text { MS } \\
\text { C6 } \\
\text { T4 inc } \\
\text { T4 } \\
\text { T4 } \\
\text { T10 inc } \\
\text { C6 } \\
\text { T4 inc } \\
\text { T4 } \\
\text { L2 inc } \\
\text { T10 } \\
\text { T3 } \\
\text { T7 } \\
\text { T7 } \\
\text { T9 inc } \\
\text { T9 } \\
\text { T5 inc } \\
\text { C7 } \\
\text { T12 } \\
\text { T8 } \\
\text { T6 } \\
\text { T11 } \\
\text { T9 } \\
\text { T2 inc } \\
\text { T9 }\end{array}$ & $\begin{array}{l}234 \\
234 \\
234 \\
234 \\
234 \\
234 \\
234 \\
234 \\
\text { uncertain } \\
234 \\
234 \\
234 \\
234 \\
234 \\
34 \\
\text { uncertain } \\
234 \\
234 \\
234 \\
34 \\
234 \\
\text { uncertain } \\
234 \\
234 \\
34 \\
34 \\
234 \\
234 \\
234 \\
234 \\
34 \\
234 \\
234 \\
234 \\
234 \\
234 \\
234 \\
234 \\
234 \\
23 \\
234 \\
34 \\
234 \\
234 \\
234 \\
234 \\
234 \\
234 \\
234 \\
234 \\
\end{array}$ & $\begin{array}{l}2,3 \\
2 \\
2,3 \\
2,3 \\
2,3 \\
2,3 \\
2,3 \mathrm{R} \\
2 \mathrm{R} ? \\
2,3 \\
2 \\
\text { none } \\
2,3 \mathrm{~L} \\
3 \\
\text { none } \\
\text { none } \\
2 \mathrm{R} \\
2,3 \\
\text { none } \\
3 \mathrm{~L} \\
2,3 \\
\text { none } \\
+ \\
2,3 \\
3 \\
3,4 \\
2,3 \\
2,3 \\
2,3 \mathrm{~L} \\
2,3 \mathrm{~L} \\
3 \mathrm{~L} \\
2,3 \\
2 \\
+ \\
2 \\
2 \\
2,3 \\
2,3 \\
2,3 \\
2 \\
2 \\
2 \mathrm{n} \\
2 \\
2,3 \\
2,3 \\
2,3 \\
2\end{array}$ & 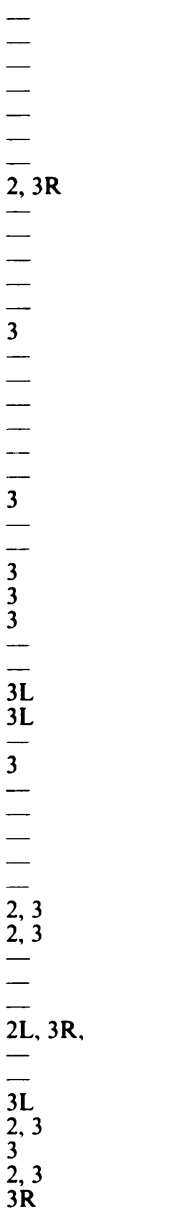 \\
\hline
\end{tabular}

* Spinal cord compression.

+Probable fat embolism.

†Facts not known.

operation that a sufficient efferent nerve supply to the detrusor survived. In the majority, cystometry sufficed; if systolic contractions to at least $50 \mathrm{~cm} \mathrm{H}_{2} \mathrm{O}$ in a man or at least $30 \mathrm{~cm} \mathrm{H}_{2} \mathrm{O}$ in a woman occurred on filling, this was good enough evidence. A few patients had areflexic bladders on cystometry, or had only low compliance as evidence of reflex activity. In these, the electroejaculation procedure ${ }^{7}$ was used whilst the bladder pressure was being recorded through a catheter, and the patient was accepted for implantation if an adequate rise in bladder pressure could be provoked, using contraction of the gluteus medius muscle (that is stimulation of the superior gluteal nerve) as a guide to finding the relevant part of the pelvic autonomic plexus. Eight patients had indwelling catheters when first seen, and all the rest were incontinent, habitually wearing condom and leg-bag (bed-bag at night) if male, and plastic pants and pads if female. To achieve continence was the main aim in the majority of patients. Elimination of urinary infection was the main aim in a few and an important secondary aim in most.

Follow-up times Patients are numbered in table 1 in chronological order of their operations. Patient 1 received her implant in 1976, 2 and 3 in 1978,4 to 7 in 1979,8 and 9 in 1980,10 and 11 in 1981,12 to 20 in 1982,21 to 37 in 1983 , 


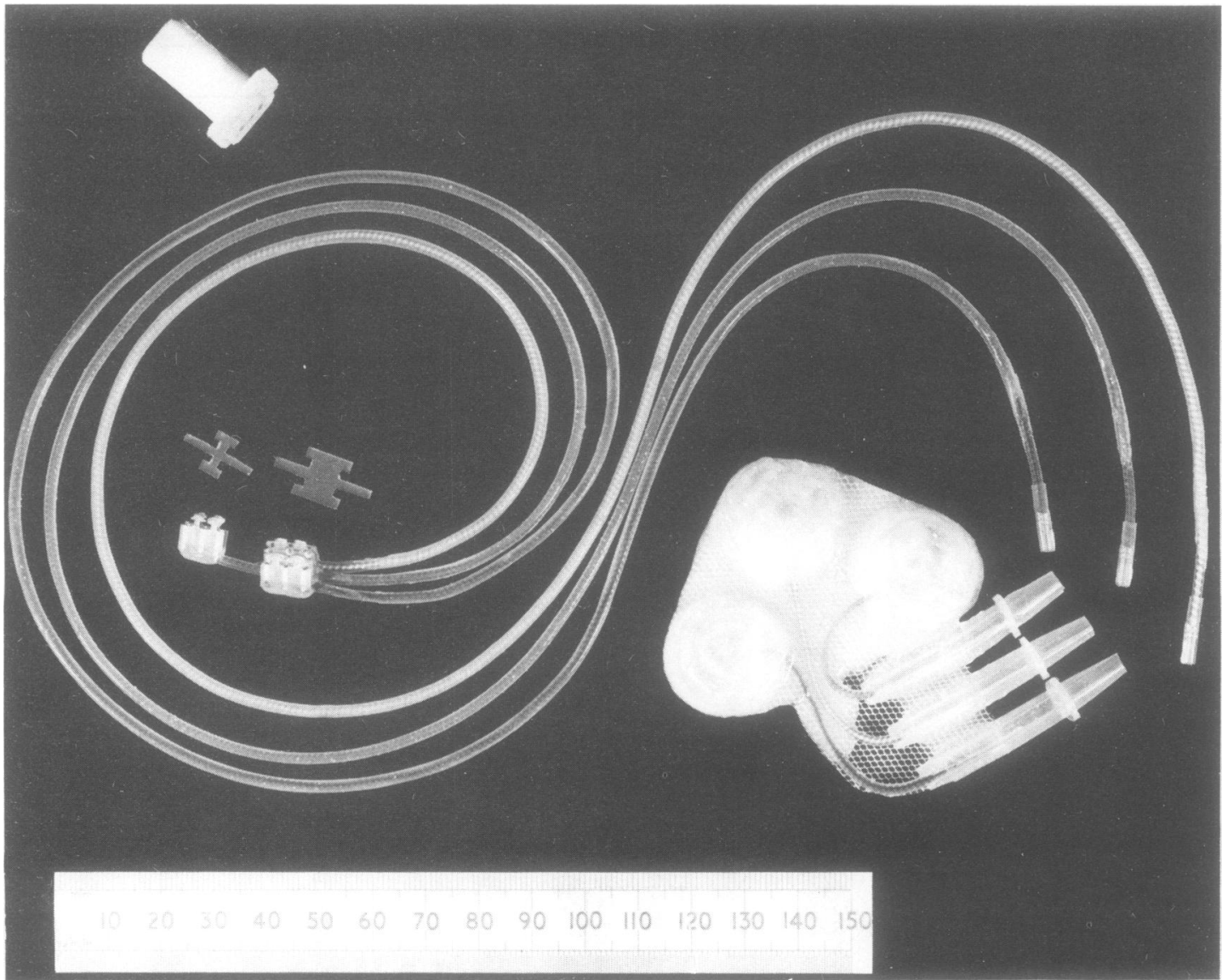

Fig 1 The cables, lying roughly in $S$ shape, end on the left in the "books" that contain the platinum foil electrodes and on the right in sockets which will fit into plugs in the receiver block. Just above the books are their silicone rubber roofs. In the upper left corner is the sleeve for preventing leakage of CSF along the cables. Below the right half of the set of cables is the receiver block. Its three output cables end in 3-pin plugs, which in this picture lie concealed in the jackets that will protect the plug-and-socket connectors after joining, but similar ones are visible in fig $2 a$ of reference 5.

and 38 to 50 in January-July 1984. All the 49 surviving patients have been seen or telephoned in March-August 1985, by one of us for the 44 living in England, Scotland or France, and by Prof $\mathrm{E}$ Arnold for the 5 living in New Zealand, and asked about use of the implant, continence status, erection (if male) and symptoms of urinary infection. Follow-up urodynamic studies have been done once within the first postoperative year on all patients except no. 1, and twice on a few patients. They were done by one of the authors for all but two of the Maudsley patients and all Oxford, London Hospital, Maida Vale and Birmingham patients. For the Sheffield, Edinburgh, Christchurch, and Le Mans patients they were done in Sheffield, Edinburgh, Christchurch and Le Mans respectively. For two Maudsley patients (11 and 13) they were done in Southport.

\section{Methods and Results}

Implants Figure 1A shows the implant that was used for patients $23-50$, and with minor differences for patients 12-14 and 16-21. It was designed in the MRC Neurological Prostheses Unit and is made by Finetech Ltd of Welwyn Garden City.

The electrodes are mounted in slots in structures that we call "books". The upper "book" has three parallel slots (like a book with front and back covers and two leaves between). The lower book has a single slot. Each slot contains three electrodes. The twelve electrodes have independent connections to the receiver block, except that each electrode of the left outer slot of the upper book is directly connected to the corresponding electrode of the right outer slot of that book. Thus the four slots allow independent stimulation of three (not four) sets of nerve fibres, the contents of the two outer slots of the upper book being necessarily stimulated together. 


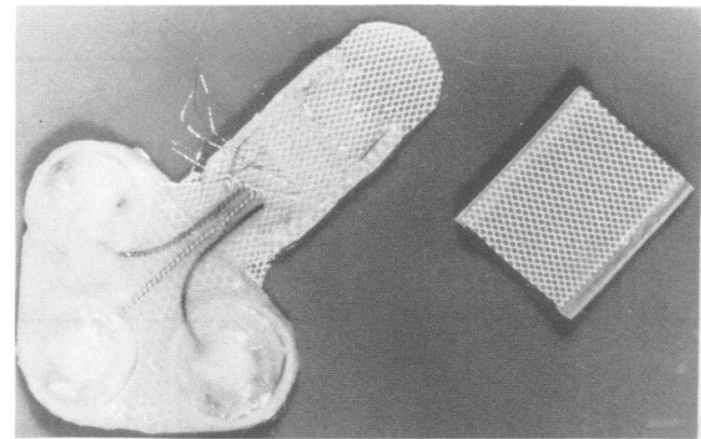

Fig 2 A replacement block for the repair operation in any patient whose receiver block fails. The size and spacing of the three receivers is exactly as in fig 1 .

The U-shaped electrodes are of a platinum foil, of width $0.7 \mathrm{~mm}$ and total length (two sides and bottom) $9.4 \mathrm{~mm}$. Those of each slot are used as a symmetrical tripole, the middle electrode being cathode and the end electrodes anodes in parallel. If such a tripole is perfectly made, and if fibrous tissue grows symmetrically, external current flow should be always zero and stimulation restricted entirely to the root within the slot. This is roughly but not exactly achieved. To have the area of the anodes greater than the cathode minimises electrode corrosion, ${ }^{8}$ and corrosion has been shown in one of our patients (no. 7) to be so slight as to be undetectable after three years of use. ${ }^{9}$

The implants of patients $1-11$ were made in the Neurological Prostheses Unit. Those of patients 1 to 9 have electrodes of platinum-iridium wire instead of platinum foil. These have surface area about three times lower and resistance about three times higher than the foil electrodes. They are connected as dipoles in patients 1 and 2, as symmetrical tripoles in the lower books of patients 3, 7,8 and 9 and the upper

Table 2 Present state of the implants

\begin{tabular}{lc}
\hline State & Number \\
\hline Removed & 1 \\
Patient dead (suicide) & 1 \\
Intact but not in use & 5 \\
In use & 43 \\
Total & 50 \\
\hline
\end{tabular}

book of patient 3 , and as unsymmetrical tripoles of the kind described and justified in reference 4 in the lower books of patients 4,5 and 6 and the upper books of patients 4-9. Patients 10 and 11 are the first to have foil electrodes. These are arranged as tripoles, and are like those of the Finetech implants used for patients 12-14, 16-21 and 23-50, except that in the upper book they are unsymmetrical as described in reference 4.

Patient 15 has a Finetech implant that is unusual only in having a 2-slot instead of a 3-slot upper book. In patients 22 and 42 the lower book was cut off at operation because it was not needed. In patient 22 the upper book was also modified by removing its partitions.

The cables of the implants are described in reference 10. They consist of three (occasionally four) helices of $95 \%$ platinum $5 \%$ iridium wire embedded in silicone rubber. When 4-wire cables have been used, two in parallel supply the cathode and one supplies each anode. Otherwise there is a wire for each electrode.

Connection between cables and receivers has been by 3-pin plugs and sockets for patients 10-50 inclusive. These are described in reference 11 .

The receiver blocks of the implants used for patients 12-21 and 23-50 were as shown in fig 1B. Those used for patients 10 and 11 were as shown in fig $2 \mathrm{a}$ of reference 5 . The circuit ${ }^{12}$ has been the same for every receiver, except that larger coils, and correspondingly different circuit-element values, are now in use in patients 4 and 22 . In patient 4 these larger coils are arranged morphognostically. ${ }^{13}$ Eight patients (nos. 2, 3, 4, 10, 22, 28, 29 and 39) have needed to have receiver blocks replaced. Figure 2 shows the replacement block used for patient 28 (the most recent replacement). The connections to the cables already in place were made by tunnel block. For the principle and constructional details of tunnel blocks see reference 14, and for the technique of using them see reference 12. Similar tunnel blocks, but without covers, were used in connecting the original receiver blocks in patients 1 to 9 . These receiver blocks were in other respects like fig $2 \mathrm{a}$ of reference 5 . External equipment This consists of an array of three radio transmitters, transmitting at 9,7 and 9 $\mathrm{MHz}$, joined by a cable to a box containing pulsegenerating circuits and rechargeable batteries. It is

Table 3 Residual urine volumes ( $\mathrm{ml}$ )

\begin{tabular}{|c|c|c|c|c|c|c|}
\hline & $0-30$ & $31-60$ & $60-200$ & $201-400$ & Over 400 & Total \\
\hline $\begin{array}{l}\text { Pre-operative } \\
\text { Post-operative }\end{array}$ & $\begin{array}{r}3 \\
28\end{array}$ & $\begin{array}{r}3 \\
12\end{array}$ & $\begin{array}{r}21 \\
3\end{array}$ & $\begin{array}{l}8 \\
1\end{array}$ & $\begin{array}{l}9 \\
0\end{array}$ & $\begin{array}{l}44 \\
44\end{array}$ \\
\hline
\end{tabular}

Four patients whose implants have never been used and two patients for whom facts are not known to us are excluded. 
Table 4 Continence

\begin{tabular}{|c|c|c|c|c|c|}
\hline & & $\begin{array}{l}\text { Continent day and } \\
\text { night }\end{array}$ & Continent at night & $\begin{array}{l}\text { Incontinent or with indwelling } \\
\text { catheter }\end{array}$ & Total \\
\hline Implant in use & men & 21 & 4 & 9 & 34 \\
\hline & women & 8 & 1 & 0 & 9 \\
\hline Implant not in use & men & 1 & 0 & 3 & 4 \\
\hline & women & 0 & 0 & 2 & 2 \\
\hline Patient dead & woman & $1^{*}$ & 0 & 0 & 1 \\
\hline Total & & 31 & 5 & 14 & 50 \\
\hline
\end{tabular}

*Continent for 3 years, up to the week of her death.

illustrated in fig $2 \mathrm{~b}$ of reference 5 .

Surgical technique The procedure used for patients $2-9$ and $11-13$ is described in reference 5 . Variations in subsequent operations have not been of major importance. The procedure that we now consider best and the variants that we think are reasonable alternatives are set out in detail in reference 12. The endresult usually aimed at is to have the left and right $\mathbf{S 2}$ anterior roots trapped in the left and right slots respectively of the upper book, the left and right S3 anterior roots trapped together in the middle slot of the upper book, and the left and right S4 and S5 roots trapped without separation of anterior and posterior in the lower book. Decisions not to trap S2 were made in six patients. Two were women ( 26 and 42 of table 1 ) in whom stimulating the $S 2$ roots during the operation gave no rise in bladder pressure, and four were men $(15,20,25$ and 31$)$ who had good reflex erections and did not want to risk losing them. A decision not to trap S4 was made in one man (40) because he had intact pain sensitivity, and stimulation of unsplit roots would certainly have been painful. The roots trapped were uncertain in patients 9 and 16 because of anatomical anomalies, and in patient 22 because of very severe arachnoiditis. One or more $\mathrm{S} 2$ or $\mathrm{S} 3$ roots were trapped without separating anterior from posterior in about half the patients (details in table 1), because fibrosis made separation too risky.

Present state of the implants This is shown in table 2. The implant which was removed (except for the part within the spinal canal) is that of patient 1 . This implant was never useful, chiefly because attempts to use it caused pain. The patient who committed suicide was no. 7. Post-mortem observations on her implant are described in reference 9 . The implant was working very well up to the day of her death. The five implants that are intact but not in use are those of patients 23 (electrical failure, not yet repaired), 35 and 49 (attempts to use them cause pain), 45 (incomplete recovery from root damage) and 46 (using indwelling catheter for controversial reasons, though implant works well).

Residual urine volumes Pre-operative residual urine volumes were measured for all patients except five who had indwelling catheters until their operations and could not void when the catheters were removed $(2,9,19,32,49)$. Post-operative residual urine volumes have been measured for all patients except the four who have not used their implants $(1,35,45,49)$. Table 3 is compiled from the measurements. Where several are available, the last pre-operative and the last post-operative are used. No patient had a higher residual volume after the operation.

Continence Two of the 12 women $(35,38)$ and 6 of the 38 men habitually used indwelling catheters before their operations. All the 10 women without catheters and all except one (case 40) of the 32 men without catheters were severely incontinent, day and night. All the severely incontinent men habitually wore condoms day and night.

Postoperatively, 22 men and eight women are now continent, day and night, and patient 7 , who died, was fully continent up to the week of her death. Another four men and one woman are continent at night. Table 4 shows details.

Ureteric reflux Seven patients $(3,6,9,23,32,33,50)$ showed reflux on one or both sides at pre-operative cystography. Three of these $(3,23,32)$ still refluxed at post-operative cystography at 4 years, 10 months and 5 months respectively. The other four did not, as follows.

Patient 6 did not reflux preoperatively during pas-

Table 5 Change in bladder capacity

\begin{tabular}{lllll}
\hline & \multicolumn{3}{l}{ Post-operative minus pre-operative bladder capacity (ml) } \\
\cline { 2 - 5 } & $30-100$ & $110-200$ & $210-400$ & $410-700$ \\
\hline Posterior roots cut & 0 & 1 & 5 & 4 \\
Posterior roots not cut & 1 & 2 & 6 & 0 \\
\hline
\end{tabular}


sive filling, but only during a reflex contraction (at $200 \mathrm{ml}$ filling) to $100 \mathrm{~cm} \mathrm{H}_{2} \mathrm{O}$. This was grade 1 reflux on the right side only. Two and a half years after his operation the bladder capacity was $450 \mathrm{ml}$, and no reflux occurred during passive filling to this volume or during implant-driven micturition at $110 \mathrm{~cm} \mathrm{H}_{2} \mathrm{O}$ voiding pressure or (after lowering the pulse frequency) at $70 \mathrm{~cm} \mathrm{H} \mathrm{H}_{2} \mathrm{O}$ voiding pressure.

Patient 9 refluxed (grade 2, on the left) at $250 \mathrm{ml}$ filling preoperatively without any reflex detrusor contaction. Sixteen months after his operation, his bladder filled to $1000 \mathrm{ml}$, he voided at a pressure of up to $42 \mathrm{~cm} \mathrm{H}_{2} \mathrm{O}$, and there was no reflux either during filling or during voiding.

Patient 33 had refluxed up the right ureter (grade 1 or 2) at all of four pre-operative examinations. On the first of two post-operative examinations, 10 weeks after implantation of the stimulator, he showed rightsided reflux (grade 1) on passive filling, but no further reflux during implant-driven voiding. On reexamination 11 months after implantation, there was no reflux on filling to $500 \mathrm{ml}$, and no reflux during implant-driven voiding even when (with stimulus parameters which we then promptly changed to avoid such pressures) the detrusor pressure reached $130 \mathrm{~cm}$ $\mathrm{H}_{2} \mathrm{O}$.

Patient 50 refluxed (grade 1 on the left) at $380 \mathrm{ml}$ filling preoperatively, during a weak reflex detrusor contraction that reached only $32 \mathrm{~cm} \mathrm{H}_{2} \mathrm{O}$. At reinvestigation after his stimulator had been implanted and in use for only 5 weeks, he filled to $500 \mathrm{ml}$ without reflux. Reflux occurred on voiding at a pressure of 90 $\mathrm{cm} \mathrm{H}_{2} \mathrm{O}$, but none during a second voiding when the pulse frequency had been reduced to bring the voiding pressure down to $64 \mathrm{~cm} \mathrm{H}_{2} \mathrm{O}$.

No patient showed reflux at postoperative cystography who had not at pre-operative.

Bladder capacity Table 5 shows observations on the volume at which systolic reflex contractions occurred ("bladder capacity") at preoperative and postoperative cystometry in nineteen patients for whom both cystometries were done at King's College Hospital. Patients who showed no systolic contractions at pre-operative cystometry $(4,12,27,36,37,40)$ are excluded.

Ten of these 19 patients had one or more of the S2

Table 6 Frequency and severity of symptomatic urinary infections (patients'opinions)

\begin{tabular}{lr}
\hline Unchanged & 5 \\
Fewer & 31 \\
More & 2 \\
Total & 38 \\
\hline
\end{tabular}

The table excludes four patients whose implants have never been used, and five New Zealand and three French patients who have not been asked about urinary infections. and $\mathrm{S} 3$ posterior roots cut for the purpose of diminishing or abolishing bladder reflex activity. Table 5 seems to show that this was successful. In all ten patients the bladder capacity was increased after the operation by more than $100 \mathrm{ml}$, and in nine of them by more than $200 \mathrm{ml}$.

In the nine patients whose posterior roots were not cut, the bladder capacity did not increase so much, but in all nine it did increase. Part of this increase, and perhaps most of it, may be attributed to accidental damage to the posterior roots. In three of these patients $(7,11,31)$ we know there was some damage, because tactile sensitivity previously present was lost after the operation in one S3 dermatome. On the other hand patient 28 , who was also in this group and had posterior column sparing, lost no tactile sensitivity, but his bladder capacity increased by $120 \mathrm{ml}$. Urinary infections Urine cultures have been done so irregularly that we can make no firm statement as to whether the implants help in getting the urine sterile. Theoretically they should do so, because of the lower residual volumes, and we have published culture results that show slight improvements in the proportion of sterile cultures (ref 5). Symptomatic urinary infections certainly decrease, as table 6 shows. Three of the five patients reporting no change said they had no urinary infections before or after implantation.

Changes in the bladder The degree of trabeculation seen in intravenous urography or cystography was reported by us $\mathrm{s}^{56}$ as diminished after $1 \frac{1}{2}$ to 3 years of use of the implant in patients $3,6,7,9,12,14$ and 15 $(2,5,6,8,10,12$ and 13 in the numbering of those references). Post-mortem examination of patient 7 showed normal kidneys and a normal smooth bladder. Radiological evidence of decreased trabeculation has now been seen also in patients $29,30,31,33,39$ and 40 . No patient has shown evidence of increased trabeculation.

Changes in the ureters and renal pelves Intravenous urography has been done since operation in all patients who received implants before 1983 (two or three times in some of these), and in the majority of the patients who received implants in 1983 and 1984 . In all but two there has been no significant change, as compared with pre-operative examinations. One patient (no. 8) showed in April 1985 slightly but definitely greater dilatation and clubbing of the calyces than in February 1982. One patient (no. 46), who had a severe illness due to urinary infection following post-operative urodynamic study, shows impaired excretion in a recent intravenous urogram. Need for subsequent sphincterotomy In one patient (no. 19), the implant gave poor voiding until, three months later, he had a transurethral sphincterotomy. It has given excellent voiding ever since. The same procedure was almost done on patient 32 , but read- 
justment of the stimulus parameters, done on the day before sphincterotomy was to have been done, gave so great an improvement in the voiding that the sphincterotomy was unnecessary.

Patient 8 is under consideration for sphincterotomy because of the deterioration in his renal calyces.

Continuous low-amplitude stimulation for continence Patients 13 and 22 used this for a time, but have not done so recently. Patient 3 still uses continuous stimulation at night, and with its help is continent at night.

Implant-driven erection Of the 38 male patients, 26 have been able to produce penile erection by means of the implant. The roots that have to be stimulated are mainly or exclusively $\mathbf{S} 2$ in 20 patients, and mainly or exclusively $S 3$ in 6 patients $(4,5,13,20,21,24)$. Stimulation of the $S 4$ roots has not caused erection in any patient. In 11 patients attempts to produce erection by means of the implant have been made, but have failed. Eight of these $(3,6,8,9,14,37,44,45)$ had all three presumably appropriate pairs of roots trapped, and the others $(15,25,31)$ only the $S 3$ and $S 4$ roots. For one patient (49) no attempt to produce erection has been made.

When it can be produced, the erection always lasts without decrement for as long as stimulation continues, even as long as an hour. In the first few weeks after operation it was good (penis certainly stiff enough for coitus) in 20 patients, fair (penis could be bent through $45^{\circ}$, so coitus would be difficult) in one (patient 48), and poor (obvious swelling of the penis, but stiffness insufficient for coitus) in five $(14,19,20$, $23,30,46)$.

In five patients $(4,10,19,30,32)$ there has been definite deterioration in implant-driven erection during months or years after implantation, and in no patient has the quality of implant-driven erection been better a year after implantation than in the first month. This contrasts sharply with the findings on micturition, where the performance of the implant is sometimes much better at a year than in the first month, and never worse.

Implant-driven erections can remain good for a long period, as is illustrated by patients 2 (7 years), 5 (6 years) and 11 (4 years).

Effect on bowel function The majority of patients report that when the implant is brought into use, the frequency of defaecation increases. A common change is from once in two days to every day. Some patients regard this as an advantage, some as a disadvantage, and some as neutral.

In about 10 patients we have observed a rise in rectal pressure, regularly produced by stimulation of the $\mathbf{S 4}$ (or less commonly the $\mathrm{S3}$ ) roots. In the majority of patients we have not tested for this. It seems usually to be of little functional importance, but a few patients use S4 and/or S3 stimulation as an aid to defaecation, and in one or two it works so well that manual evacuation which was formerly needed has become unnecessary.

Pain on using the implant Seven patients $(1,7,20$, $26,35,40,49$ ) could before operation distinguish the sharp from the blunt end of a pin in sacral dermatomes (patient 35 only with difficulty and only in the S4 dermatomes). All of these found the use of the implant to some extent painful, though care had been taken to separate anterior from posterior roots, and in patient 49 the relevant posterior roots had been cut. In patients $7,20,26$ and 40 the pain was very mild, and did not prevent the implant from being used. In patient 1 it was of moderate severity, and was one of the reasons why this implant was never useful. In patients 35 and 49 it was severe, and has completely prevented the implant from being used.

Autonomic dysreflexia Rise in blood pressure on using the implant has not been sufficient to cause severe headache in any of the 50 patients reported here. It has sometimes caused mild headache, but not more than does reflex micturition in the same patient.

It should, however, be pointed out that one tetraplegic patient operated on after completion of the first 50 is unable to use his implant, because attempts to use it cause an unacceptable amount of dysreflexia.

Damage to roots at operation Accidental damage to posterior roots (see also the section on "Bladder capacity") can be proved or disproved only for the 13 patients who before operation had tactile sensitivity in their sacral dermatomes $(1,7,11,20,21,26,28,31$, $33,35,40,42,49)$. Damage was done in patients 7 (right S4, left S2), 11 and 31 (right S3) and 40 (right S2). There was no accidental damage in the other nine patients. The sensory loss in patient 7 was present and unchanged a year after her operation, and was not examined after that. In patients 11 and 40 it is still present and unchanged, as one might expect, since although the afferent fibres in the roots almost certainly regenerate,${ }^{15}$ restoration of function would require the re-establishment of synaptic connections within the cord.

Accidental damage to anterior roots shows itself by absence of some of the skeletal muscle responses that one expects to obtain on stimulating by means of the implant in the early weeks, and also by loss of anal sphincter tone. On this evidence, damage was done in 23 patients: 3 (both S2, both S4, left S3), 4 (right S3), 6 (left S2), 8 (all 6 roots), 9 (uncertain which roots), 10 (left S3), 12 (left S2, left S3), 18 (both S3), 19 (right S3), 20 (left S3), 21 (left S2), 22 (uncertain which roots), 24 (right S2), 30 (left S3), 32 (right S2), 36 (both S3), 37 (right S2), 39 (left S2, left S3, both S4), 43 (right S3), 44 and 45 (uncertain which roots), 46 (both S2, both S3), and 47 (left S2). Within a year, 
most of the lost skeletal muscle functions recovered substantially, and many of them completely.

Of these 20 patients whose skeletal muscle responses to stimulation through the implant showed that there had been anterior root damage, 11 were nevertheless able to use their implants as sole means of micturition within a week of implantation. But patient 8 has never been able to do this, though he voids well by a combination of expression and use of the implant, and in patients $3,39,22,46,18,19,10$ and 36 use of the implant as sole means of micturition was not possible until 10, 8, 6, 6, 4, 3, 2 and 2 months respectively after implantation.

Besides delaying use of the implant for micturition, root damage caused troublesome faecal incontinence during the first year in patients 8 and 39. No other patient has complained of faecal incontinence, though most have been asked about it.

The worst cases of anterior root damage occurred in patients $(3,8,22)$ who were found at operation to have severe arachnoiditis affecting all the relevant roots. Since the long-term results in patients 3 and 22 are excellent, there is probably no need to obtain radiculograms in advance to diagnose such patients and exclude them.

Leakage of cerebrospinal fluid In 14 patients, CSF leaked along the cables after implantation and formed a cystic swelling around the receiver block. Such swellings appeared or became worse after many hours of sitting each day, and disappeared or became much smaller each night. In one patient (39) CSF leaked through the wound over the receiver block, and after a few days a corner of the block herniated through the skin. The emergency was treated by cutting all three cables through a new small incision about $12 \mathrm{~cm}$ from the receiver block, and then removing the receiver block through the old incision over it. Two months later a new receiver block was implanted. The CSF leak had then ceased, without need for surgical intervention in the midline of the back. In six patients $(1,2,10,20,32,44)$ the leak ceased without any operative procedure. In seven patients $(5,6,25,27,40,43,45)$ the posterior midline incision was re-opened and the leak through the dura repaired locally. One such repair operation sufficed in each case.

Implant failures and their repair In patient 12 , one connection failed in a tunnel connector in September 1979. A new receiver block was implanted, and it is still good. In patient 3 , a diode failed in a receiver in February 1980. A new receiver block was implanted. Then in January and February 1984 two of his three cables failed in the midline of the back. We mended the breaks by inserting tunnel connectors. In patient 4 , one connection failed in a tunnel connector in December 1980 . His receiver block was replaced, but its tunnel connector failed in May 1981. The block was again replaced, but a third such failure occurred, and a third replacement was done in February 1982. He has had no further failure. In patient 6 , the S3 receiver was found to have failed in March 1983. This patient used only S4 for micturition (he is the only one to use S4 only, though many use S3 and S4 together), so there was no need to replace his faulty $S 3$ receiver. In patient 10 two of the three cables failed in the midline of the back in July-October 1984. They were mended by insertion of tunnel connectors. In patient 22, a tunnel connector failed in July 1983 . We replaced the connector and receiver block, and the replacement still works. In patient 28 the coil of one of the three receivers failed in July 1984. We implanted a new receiver block. In patient 29 one of the three plug-and-socket connectors failed in July 1984. We implanted a new receiver block. In patient 41 a plug-and-socket connector failed in March 1985. It was repaired in June 1985 . Patient 23 has very probably an implant failure of some kind. Exact diagnosis and treatment are delayed because he lives in New Zealand.

In all, the known failures are thus five tunnel connectors, four cables (two linked pairs of events), two plug-and-socket connectors, and three receivers in 154 patient-years of implant use. The design of all components which have failed has been improved since those components were made. The improving of the cables was done by Finetech Ltd before any failures in the old cables (made in the Neurological Prostheses Unit) had occurred. No Finetech cable has yet failed. The improving of tunnel connectors (now used only for repairs), plug-and-socket connectors and receivers was done mainly in response to observed failures.

Overall opinions of the users These are shown in table 7. Patient 7 is included among the 40 who are very pleased, without significant reservations, because this was her opinion up to the week of her death in September 1983. Inconveniences suffered by some of these patients which they do not consider to be significant reservations include CSF leaks, receiver failures requiring surgical replacements, temporary worsening of leg spasms, temporary increase in sweating, and impairment of reflex erections in two men whose erections were poor before the operation.

Table 7 General opinions of patients in 1985

\begin{tabular}{lr}
\hline Opinion & Number \\
\hline Very pleased, without significant reservations & 40 \\
Pleased on balance, but with reservations & 6 \\
Regret having had the operation & 4 \\
Total & 50 \\
\hline
\end{tabular}


The four dissatisfied patients are nos. 1, 35 and 45, whose implants have never been used, and no. 46, who has'suffered more harm than benefit.

Patient 49, who also cannot use his implant because of pain, is, on balance, pleased, because the posterior root section that we did at the same time as implanting the stimulator greatly increased his bladder capacity and allowed him to achieve continence by 4-hourly self-catheterisation.

Of the other six patients who are mainly satisfied, but have significant reservations, one (25) has impairment of reflex erections that were good before the operation, and two $(8,39)$ suffered faecal incontinence during several months after the operation, though this has now recovered. Patient 23 has an implant which formerly worked well and now works poorly. This is almost certainly the result of an electrical failure in the implant, which we hope soon to diagnose and cure. Patient 26, with a long history of progressive mainly spinal multiple sclerosis, was able to stand and transfer, but not walk, before the operation. Spasticity and spasms were increased and the legs weaker postoperatively. The spasticity and spasms settled over 3-4 months, and power improved slowly, and after 2 years her standing was almost as confident as before. Patient $\mathbf{4 0}$ suffered pain in the right posterior thigh for some months after the operation, and a change in pattern of spasticity which prevented him from walking with calipers (which he formerly did often, though not every day). He has still not resumed caliper walking. He thinks he now could, but would need help to re-learn.

\section{Discussion}

Continence The sacral anterior root stimulator is used by most patients only or mainly for micturition. When the animal experiments by which it was developed were done, it was intended that it should be used also for continuous activation of the rhabdosphincter to assist continence, but we have done this in only a few patients (for example ref 5, fig 7), and with only partial success. Only one patient is using continuous sphincter activation at present (September 1985). Why then is the implant so successful in achieving continence?

One factor is that the residual volume is lowered, and this in itself increases the amount of urine that can drain into the bladder before the threshold for a reflex detrusor contraction is reached. This seems to be the main factor in patients with large preoperative residual volumes and bladders that produce reflex systolic contractions only when filled to very large volumes or not at all. Such patients are nos. 3, 4, 5, 9, 12,37 , and 40 .

A second factor, which is presumably predominant in patients who preoperatively had low bladder capacities, is that the operative procedure raises the bladder capacity substantially if the S2 or S3 posterior roots are cut, and slightly even if they are not cut (table 5). Whether a definite increase in the bladder capacity always indicates some posterior root damage is uncertain. The findings in patient 28 suggest that it probably does not.

Bladder trabeculation Several patients have shown a definite decrease in trabeculation as judged from radiographs. Though trabeculation seen in radiographs may not be the same as trabeculation seen by cystoscopy, this alteration is an objective one, and (being in the direction of normality) is presumably beneficial. We have seen it in patients whose bladders were nearly atonic pre-operatively (for example nos. 3,9 , and 40) and in patients with small irritable bladders preoperatively (for example nos. 14 and 39, who had posterior roots cut, and nos. 7, 15 and 33, who did not). It seems likely that the improvement in patients whose bladders were initially almost atonic is due to the less frequent and less severe over-distension when these patients have implants. The cause of the improvement in patients who preoperatively had small irritable bladders is probably that after the operation reflex contractions are far less frequent or wholly absent, and the patient's drive box is adjusted so that implant-driven contractions are not overpowerful, never raising the bladder pressure above $90 \mathrm{~cm} \mathrm{H}_{2} \mathrm{O}$.

Ureteric reflux Patients 6, 9, 33 and 50, who refluxed at preoperative urodynamic study, did not after operation. For patient 33 there are enough observations to establish that it is a consistent alteration, which does not require that the voiding pressure be kept low, though we choose to keep it low with the aim of avoiding bladder hypertrophy. In patients 9 and 50, though there is only one pre-operative and one postoperative observation, the change after 16 months' and 5 weeks' implant use respectively is so large that it is difficult to doubt that it is due to the operation or to the change from reflex to implant-driven micturition. In patient 6 the apparent improvement could perhaps be fortuitious.

Patient 50 well illustrates the benefit from being able to control the voiding pressures by altering the pulse frequency: only by lowering his voiding pressure were we able to prevent reflux.

Erection All patients who get implant-driven erections are glad to have them, and most use them for sexual intercourse. We do not know why in eight patients, despite trapping of all three presumably appropriate pairs of roots, no implant-driven erection could be obtained. It is doubtless relevant that seven of these eight patients had damage to anterior roots, as shown by loss of skeletal muscle response, but in 
two of them $(6,37)$ the damage was purely unilateral, and in patient 14 there was no detectable damage. A likely additional factor is reflex activation of the sympathetic anti-erectile pathway ${ }^{1617}$ by stimulation of sacral posterior root fibres.

Pain on using the implant This has not occurred in any patient whose lesion seemed before operation to be complete, or to spare only posterior column function. It has, however, occurred in all the six patients who could easily distinguish the sharp from the blunt end of a pin in sacral dermatomes (though it was very mild in four of them), and it occurred and was severe for S2, S3 and S4 stimulation in one patient (35) who could make this discrimination only with difficulty in the S4 dermatomes and not at all in the S3 and S2.

The question whether there are afferent fibres (and in particular pain fibres) in anterior roots is controversial, ${ }^{1819}$ and our observations do not yet settle it, but they do have the practical implication that if a patient who retains sacral-segment pain sensitivity receives a sacral anterior root stimulator implant, there is a risk that it may be unusable.

Accidental damage to roots Though the consequences of this when it occurs have sometimes been beneficial and often trivial, severe damage can delay use of the implant for 6 to 10 months (patients 3, 8, $22,39,46)$, cause temporary faecal incontinence (patients 7 and 39), and permanently impair reflex erections (patients $3,8,25,46)$. Our opinions on what surgical procedures minimise the risk of damage are set out in reference 12.

Leakage of CSF The grommet or sleeve placed where the cables leave the dural theca ${ }^{19}$ reduces the risk of this ( 4 cases out of the first 7 , for whom grommets were not used, and 10 out of 43 since their introduction), but it has not eliminated it. Our opinions on how to reduce the risk are set out in reference 12 .

Selection of patients in future A necessary condition for suitability is proof that the bladder retains an efferent innervation and is capable of developing a pressure of at least $50 \mathrm{~cm} \mathrm{H}_{2} \mathrm{O}$ in a man and at least $30 \mathrm{~cm} \mathrm{H}_{2} \mathrm{O}$ in a woman. This can usually be proved by ordinary cystometry; if not, the electroejaculation procedure must be used (ref 7 ).

If adequate efferent innervation is proved, almost any patient with a complete or nearly-complete spinal cord transection from injury or non-progressive disease can reasonably hope for benefit from a sacral anterior root stimulator but not all are equally suitable.

For wheelchair-bound men with well-functioning reflex bladders and permanently sterile urine who do not much dislike condom collection, the risk of infecting the urinary tract by the catheterisations necessary for assessment and for regulating the implant may be judged to outweigh the advantage of continence. This would not, we think, be so for any woman, incontinence being much more burdensome to a woman because of the lack of any satisfactory urinecollecting device.

Patients with low lesions or gunshot wounds, and those who have had intrathecal injections of oily radio-opaque materials in previous investigations, are more likely than others to have fibrosis ("arachnoiditis") of the cauda equina, and the risk of damaging the roots when dissecting them is increased.

Those tetraplegic and high paraplegic patients who already have severe autonomic dyreflexia run a risk of not being able to use a sacral anterior root stimulator, as has happened to one recent tetraplegic patient, though not to any of the 8 tetraplegics among the first 50.

Continence is a smaller benefit to a tetraplegic man than to a paraplegic man, because few tetraplegic men can transfer to a toilet seat without help, and few can void from the wheelchair into a bottle. Therefore most tetraplegic men will continue to wear condoms, as all the seven in this series do. Nevertheless, they are all very pleased with their implants. The tetraplegic woman in our series benefits greatly from her continence. She needs help to transfer to a toilet seat, but a helper is available to her most of the time, and by voiding on the toilet seat 4-hourly in the day she has dry clothes and dry beds almost always, and can sleep uninterrupted for 7-8 hours.

We thank the following for permission to report patients under their care and/or for supplying us with information about patients: Mr DG Thomas (urologist) and Mr D Forster of Sheffield, Prof E Arnold and $\mathrm{Mr} \mathrm{M}$ MacFarlane of Christchurch, New Zealand, Mr J Maccabe and Dr I Janota of the Maudsley Hospital, London, Mr P Harris and Mr P Edmond of Edinburgh, $\mathrm{Mr} \mathbf{P}$ Teddy and $\mathbf{M r} \mathbf{G}$ Fellowes of Oxford and Stoke Mandeville, Prof E Hitchcock of Birmingham, Dr M Herlant and Dr P Colombel of Le Mans, France, Mr R Weeks, Mr T Varma and Mr T Stephenson of Cardiff, Mr DGT Thomas (neurosurgeon) of Maida Vale Hospital, London, Prof ES Watkins and Mr F Afshar of The London Hospital, London, Mr K Krishnan of Southport.

\section{References}

${ }^{1}$ Brindley GS. Electrode-arrays for making long-lasting electrical connexion to spinal roots. J Physiol (Lond) 1972;222:135-6P.

${ }^{2}$ Brindley GS. Emptying the bladder by stimulating sacral ventral roots. J Physiol (Lond) 1973;237:15-6P.

${ }^{3}$ Brindley GS. An implant to empty the bladder or close the urethra. J Neurol Neurosurg Psychiatry 1977;40: 358-69. 
${ }^{4}$ Brindley GS, Craggs MD. A technique for anodally blocking large nerve fibres through chronically implanted electrodes. J Neurol Neurosurg Psychiatry 1980;43: 1083-90.

${ }^{5}$ Brindley GS, Polkey CE, Rushton DN. Sacral anterior root stimulators for bladder control in paraplegia. Paraplegia 1982;20:365-81.

${ }^{6}$ Cardozo L, Krishnan KR, Polkey CE, Rushton DN, Brindley GS. Urodynamic observations on patients with sacral anterior root stimulators. Paraplegia 1984;22:201-9.

${ }^{7}$ Brindley GS. Electroejaculation: its technique, neurological implications and uses. J Neurol Neurosurg Psychiatry 1981;44:9-18.

${ }^{8}$ Craggs MD, Donaldson PEK, Donaldson $\mathrm{N}$ de $\mathrm{N}$. Performance of platinum stimulating electrodes, mapped on the limit voltage plane. Med Biol Eng Comput (In press).

${ }^{9}$ Donaldson PEK, Donaldson N de N, Brindley GS. Life of $\mathrm{Pt}$ and Pt-Ir stimulating electrodes in neurological prostheses. Med Biol Eng Comput 1985;23:84-6.

${ }^{10}$ Donaldson PEK. The Cooper cable: an implantable multiconductor cable for neurological prostheses. Med Biol Eng Comput 1983;21:371-4.

${ }^{11}$ Donaldson PEK. The Craggs connector: a termination for Cooper cable. Med Biol Eng Comput 1985;23:195-6.
${ }^{12}$ Brindley GS, Polkey CE, Rushton DN. The FinetechBrindley Bladder Controller: Notes for Surgeons and Physicians. Welwyn Garden City: Finetech, 1985.

${ }^{13}$ Donaldson N de N. Morphognostic coils: a technique for transmitting nearfield radio signals through the same space. Med Biol Eng Comput 1979;17:271-4.

${ }^{14}$ Brindley GS. A method for making and insulating many electrical connexions in an implant at the time of implantation or during a subsequent surgical procedure. J Physiol (Lond) 1975;247:2-4P.

${ }^{15}$ Ramon y Cajal S. Degeneration and Regeneration of the Nervous System. Vol 2. London: Oxford University Press, 1928: 532-4.

${ }^{16}$ Sjöstrand NO, Klinge E. Principal mechanisms controlling penile retraction and protrusion in rabbits. Acta Physiol Scand 1979;106:199-214.

${ }^{17}$ Brindley GS. Physiology of erection and management of paraplegic fertility. In: Hargreave TB, ed. Male Infertility. Berlin: Springer, 1983:261-79.

${ }^{18}$ Coggeshall RE, Applebaum ML, Fazan M, Stubbs TB, Sykes MT. Unmyelinated axons in human ventral roots a possible explanation for the failure of dorsal rhizotomy to relieve pain. Brain 1975;98:157-66.

${ }^{19}$ Floyd K, Koley J, Morrison JFB. Afferent discharges in the sacral ventral roots of cats. J Physiol (Lond) 1975;259:37-8P. 